\title{
El nuevo orden económico internacional
}

\section{The New International Economic Order}

\author{
Dr. Julio Carlos Lozano Hernández *https://orcid.org/0000-0003-3782-1892
}

http://dx.doi.org/10.21503/lex.v18i26.2181

* Doctor en Derecho y Abogado por la Universidad de San Martín de Porres. Magíster en Derecho Empresarial por la Universidad de Lima. Cuenta con estudios de Postgrado en Derecho Europeo de los Negocios en la Universidad de Alicante; en Derecho Empresarial de la Unión Europea en la Universidad de Navarra, en Arbitraje Comercial Internacional y Empresa y Medio Ambiente en la Washington College of Law de la AU, en Instituciones Jurídicas del Mercado en la UPC. Es Especialista en Electricidad por la Sociedad Nacional de Minería, Petróleo y Energía, y además Especialista en Seguridad y Defensa Nacional por el MINDEF. Miembro fundador del Instituto Iberoamericano de Derecho Concursal. Capitulo peruano. Árbitro de la nómina de la Cámara de Comercio de Lima, de la Pontificia Universidad Católica del Perú, del Organismo Supervisor de Contrataciones del Estado (OSCE), entre otros. Catedrático de pre y posgrado en diversas universidades del país. Ha sido Vocal de la Sala de Defensa de la Competencia del Indecopi del año 2012 al 2017 y Presidente de dicha Sala el año 2016. Se ha desempeñado en importantes funciones como la de Asesor de la Presidencia del Consejo de Ministros y Gerente Corporativo Legal y de Regulación de Distriluz. Autor de libros, expositor y panelista sobre temas de su especialidad. Perú

Correo electrónico: jlozano@lozanohernandezabogados.com

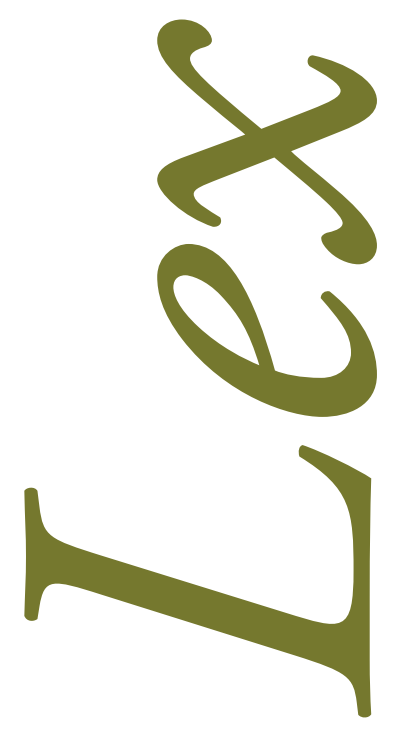




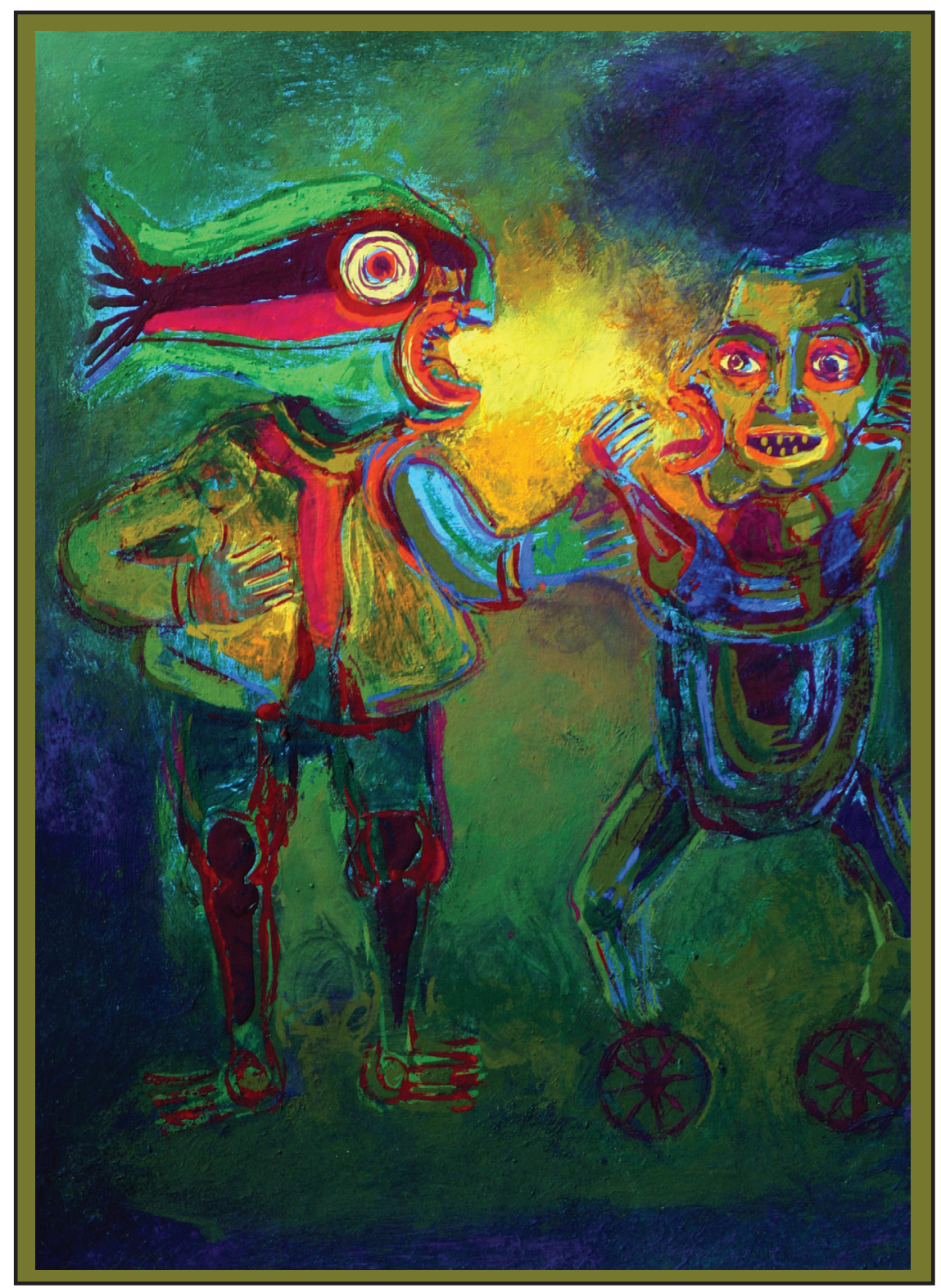

Mira que te explico. Mixto, 2000. Artista plástico peruano, Alberto Quintanilla (Cusco 1934). 


\section{RESUMEN}

Es evidente que hoy dada la pandemia y otros factores existen grandes problemas de orden económico, incluso en los países más desarrollados que también están sufriendo estas crisis y lo lamentable es que tratan de solucionarlo con políticas de muy corto plazo y que sólo atienden la parte interna y particular de su crisis, desconociendo el concepto acuñado a nivel de las Naciones Unidas; acotado a la nueva estructura económica transfronteriza; como Nuevo Orden Económico Internacional, que propugna ayudar a establecer relaciones económicas más justas y de esta manera a contribuir a mejorar el destino de las poblaciones de diversas partes del mundo, todos estos principios que existen y que de alguna manera generarían, con una visión más amplia por parte de estas naciones, un desarrollo más equilibrado en el mundo, por lo que para lograr este objetivo sería necesario interiorizar en las políticas internacionales de las naciones en desarrollo el respeto irrestricto de las ideas propugnadas vinculadas a este concepto y que mediante el presente trabajo podemos conocer y entender.

Palabras clave: empresa, orden económico, insolvencia trasfronteriza, agencia de competencia, negocios.

\section{ABSTRACT}

It is evident that today, given the pandemic and other factors, there are major economic problems, even in the most developed countries that are also suffering from these crises and the regrettable thing is that they try to solve it with very short-term policies and that only attend the internal part and particular of its crisis, ignoring the concept coined at the United Nations level; limited to the new cross-border economic structure; as the New International Economic Order, which advocates helping to establish fairer economic relations and in this way to contribute to improving the destiny of the populations of various parts of the world, all these principles that exist and that in some way would generate, with a more vision wide on the part of these nations, a more balanced development in the world, so that to achieve this objective it would be necessary to internalize in the international policies of the developing nations the unrestricted respect of the ideas advocated linked to this concept and that through the present work we can know and understand.

Key words: company, economic order, cross-border insolvency, competition agency, business. 


\section{INTRODUCCIÓN}

La nueva realidad que ha irrumpido la forma como interactuamos es la globalización, que en palabras de Christian Larroument "es entendida como la apertura de los mercados en todos los países del mundo, donde funcionan los operadores del comercio internacional de bienes y servicios"

Esto ya no tiene relación alguna con la expresión acuñada en la VI asamblea especial de la ONU, del año 1974, que hace referencia de modo genérico a las peticiones que presentaban los países subdesarrollados a los desarrollados, relativos a las reglas de funcionamientos de la economía internacional. Sin embargo, su actual y verdadera importancia ha ido adquiriendo más relevancia con el paso del tiempo, por la cada vez mayor importancia del comercio internacional y su estrecha vinculación con el desarrollo de los países y sobre todo con la posibilidad de eliminación de pobreza que el permitir su desarrollo libre y competitivo traen, sin lugar a dudas, en donde se implementa responsablemente.

Por lo que ante esta nueva realidad, se requiere de reglas que se adapten a esa realidad, en la cual surge un renacimiento del derecho internacional, ya sea a través del multilateralismo o el bilateralismo, que ha traído además el resurgimiento de la Lex Mercatoria ${ }^{2}$ que implicó un orden jurídico que utilizaban, precisamente, los comerciantes en los albores del desarrollo social y de vinculación transnacional para resolver las diferencias que pudieran surgir del normal desarrollo de actividades mercantiles entre ellos, que como es humano entender, presentaban circunstancialmente diferencias en la ejecución o cumplimiento de los contratos celebrados que era fundamental resolver con equidad y atendiendo a las diferencias entre comerciantes de las más diversas partes del mundo que encontraban su confluencia en el desarrollo de sus actividades comerciales con sus pares surgidos de diferentes latitudes, con diferentes usos y costumbres e inclusive maneras de entender la justicia al menor costo posible.

1. C. Larroument, Internacionalizacion del Derecho en un Mundo Globalizado, (Lima: Fondo Editorial de Universidad San Martín de Porres, 2008), 13 y siguientes.

2. F. De Trasegnies Granda, “¿Lex mercatoria rediviva? Primera parte: De la edad media a la posmodernidad”, Revista Peruana de Arbitraje, Nº 3 (2006), 15-51. 
Con la finalidad de resolver estas controversias, ya sea mediante el régimen de solución de conflictos oficial u ordinario, entiéndase por ante los tribunales de justicia de cada país, donde el estado cumple esta función mediante funcionarios capacitados para ello, o mediante arbitraje, que es el mecanismo alternativo de solución de conflictos más recurrido en estos casos se debe de entender que para facilitar las soluciones se pueden usar acuerdos globales, regionales o incluso bilaterales.

En el caso del multilateralismo, puede comprender:

a) Acuerdos globales, como los acuerdos en el marco de la Organización Mundial de Comercio,

b) Acuerdos regionales, como los acuerdos que se dan en el marco de la Unión Europea, CAN, MERCOSUR.

En el caso del bilateralismo, comprender la mayoría de tratados de libre comercio, como podría ser el Acuerdo de Complementación Económica entre nuestro país y los Estados Unidos de América o cualquier otro que el Estado, que responsablemente, haya suscrito.

Sin embargo, los acuerdos entre estados no es lo único que regula las relaciones comerciales en el marco del derecho internacional, sino también existe lo que Christian Larroument denomina "Derecho Transnacional o derecho a-nacional, que son reglas de derecho que no tienen un origen ni estatal ni internacional"3

\section{ORDEN PÚBLICO TRANSNACIONAL}

Por ende, si para el derecho nacional, existe un orden público nacional, para este derecho transnacional existe un orden público transnacional, que constituye un límite a la libertad contractual, pero dicho concepto si bien parece indeterminado, debe tener fuentes que permitan dotarlo de un contenido más predecible.

$\mathrm{Al}$ respecto debemos referir que el mismo Larroument nos refiere, con lo que coincidimos, que existen objetivamente tres fuentes transnacionales que son:

a) Principios comunes a las naciones civilizadas.

b) La costumbre o la práctica mercantil.

c) Los principios redactados por organismo privados.

Hay que entender que el derecho transnacional, es un derecho de aplicación supletoria, ya que va primar lo establecido expresa o implícitamente por las partes, siendo aplicable de forma excluyente la ley estatal escogida o la norma internacional (p.e. Convención de Viena en materia de los contratos de compra-venta, Convención de Roma de 1980 en materia de obligaciones contractuales, tratados de libre comercio...).

3. C. Larroument, Internacionalizacion del Derecho en un Mundo Globalizado, op. cit., 15 y siguientes. 
Lo cierto es que el mundo globalizado, como lo entendemos hoy, ha permitido un impulso fundamental del derecho privado que ha generado un desarrollo sustentable y que reafirma el sentido e importancia del Derecho Privado sustantivo que trasciende fronteras y naciones, por ello en la época actual paralelamente al Derecho Privado Nacional está surgiendo otro Derecho Privado que atraviesa las fronteras y que crea nuevas instituciones y que genera la creación constante de nuevas figuras jurídicas, de contratación, de asociación, de vínculos que la interacción de comerciantes, creadores, desarrolladores o emprendedores de diversas nacionalidades que generan de manera permanente dada la imparable necesidad de satisfacer necesidades cada vez más complejas y tecnológicas.

Y esto en buena cuenta no es desde hace mucho, pues, si consideramos cuanto tiempo tiene el ser humano ocupando el planeta, y vinculado, es verdad, con problemas jurisdiccionales, más precisamente en la Edad Media surgió lo que se conoció como la Lex Mercatoria como derecho especializado de comerciantes y que en realidad, con una visión actual podemos concluir que está vinculado en estricto a un Derecho Transnacional.

Derecho Transnacional que es una realidad que no podemos negar y, que trata, desde una perspectiva objetiva, de encontrar su propio espacio y poder precisar sus contornos dentro del, normalmente hostil, medio de los derechos nacionales que pretende siempre manejar y controlar las actividades comerciales, mercantiles y de intercambio en general, situación que es objetivamente imposible de realizar cuando la actividad económica o mercantil moderna tiene generalmente, objetiva e innegablemente, elementos internacionales dentro de su desarrollo.

Cómo bien lo destacó en su momento el jurista Fernando de Trazegnies Granda en su importante trabajo titulado ¿Lex mercatoria rediviva? ${ }^{4}$ donde hace notar objetivamente que la Lex Mercatoria era un derecho transnacional por excelencia, y surgió como un derecho extraordinariamente abierto y creativo y que tenía la posibilidad de adaptarse a los cambios de manera mucho más eficaz que el posterior derecho moderno vinculado un estado central.

Por ello debemos entenderlo en la lógica objetiva de la época no como un derecho acotado o limitado al derecho estatal o "rehén del poder político cuya fuente, legitimidad y vigencia efectiva depende exclusivamente del Estado"5. (Grossi, 2004, pág. 189).

La realidad de esta época obligaba a que el derecho de la Edad Media sea un derecho de juristas atentos al sentir del pueblo, a escuchar su voz, es decir era en buena cuenta un sistema jurídico que se sostenía básica y esencialmente en el Derecho Consuetudinario decir es un derecho que surge de la idiosincrasia del pueblo, y que, por tanto no está acotado ni restringido, de modo alguno, por el poder

4. F. De Trasegnies Granda,” “Lex mercatoria rediviva? Primera parte: De la edad media a la posmodernidad” op. cit., $15-51$.

5. P. Grossi, La formación del jurista y exigencia de una reflexión metodológica innovadora, (México: Escuela Libre de Derecho la Universidad de Michoacan de San Nicolás Hidalgo, 2004), 189. 
político, lo que lo hacía un derecho objetivamente más eficiente, más útil y más acotado a la realidad de esa época, pues insistimos en esta época no existían los Estados en el sentido moderno, ni la autoridad, como la entendemos ahora, se encontraba concentrada en el Estado, sino que dicha autoridad estaba ubicada en un sin número de centros de poder, locales, gremiales e inclusive eclesiásticos, pues la iglesia, recordemos en esta época tenía una actuación e importancia que trascendía el marco religioso de su natural ubicación.

Por ello es fácil entender que ésta falta de concentración de control, solo se sostenía en la posibilidad de creación de un derecho basado en las costumbres y en lo que en su momento los comerciantes consideraban razonable a sus prácticas mercantiles habituales.

A pesar de esto no podemos negar imparcialmente que siempre existió el comercio a un nivel de mercado local, pero precisamente con el desarrollo de los pueblos y la necesidad humana de interactuar socialmente y de los comerciantes de poder proveer de bienes y servicios de la más variada naturaleza y utilidad a la mayor cantidad de clientes posible, consumidores de dicha época, es que surge la necesidad de ampliar las fronteras en esta interacción comercial.

Debemos recordar que esto surge con los primeros comerciantes que traen las nuevas maravillas descubiertas por los cruzados en el oriente como la seda, los perfumes, las especies, esto sólo por citar algunos productos, lo que podemos entender constituye la base del primer comercio internacional dentro de la pujante sociedad europea. Contribuyen en esto luego los marinos de Venecia los comerciantes ingleses, que interactuaban por el mar, dadas sus particulares y reconocidas habilidades náuticas, en lugares y con comerciantes de muy diversas y además lejanas latitudes del mundo.

Esto permitirá entender que el derecho en esa época era un derecho que está mucho más ligado a un derecho práctico y eficiente que surge de la interacción con el pueblo, que al que surge posteriormente con la creación de concepto de Estado que contiene inmerso el control y voluntad en su ejecución de los gobernantes de estas nuevas naciones. Esta realidad diferente originó, como corresponde, un derecho que busca atender la natural necesidad de solucionar los problemas propios que esta actividad transfronteriza generaba por sí.

Entendido esto, es fácil asumir que la Lex Mercatoria que hoy debemos entender como Derecho Transnacional es un Derecho que en la Edad Media sobrepasó los derechos locales y como correspondía, fue un Derecho Universal, que básicamente es un derecho extraordinario que surge con muchísima fuerza que reglamenta y ordena el comercio internacional y, en esta época claro está, todo lo vinculado además a la navegación comercial que aún en la actualidad tiene una preponderancia fundamental en la interacción mercantil que se da entre las naciones en el mundo entero.

En este sentido este Derecho Transnacional, surgido en la edad media, con el pasar del tiempo mantuvo su vigencia, pues se concentró durante siglos, por encima del Derecho Estatal, como un derecho innovador, creativo e imaginativo, pues tenía la obligación objetiva encontrar soluciones novedosas, 
razonables y eficientes para los problemas que la actividad comercial transfronteriza generada. Es un derecho que definitivamente ayudo a generar la expansión comercial que luego tuvo su innegable origen, sostén y desarrollo globalizado con la revolución industrial, que se presenta en una etapa posterior, pero este Derecho Medieval, la Lex Mercatoria innegablemente también contribuyó al desarrollo del comercio y su sostenibilidad, y vinculado a ello el desarrollo, por tanto, de las comunas y de los ciudadanos de estos pueblos vinculados a dichas actividades mercantiles, pues como es fácil de imaginar, permitía a los ciudadanos que habitaban estas localidades mejorar su calidad de vida, por lo que en esta parte de la investigación podemos concluir entendiendo que la expansión comercial no hubiera sido posible sin la creación de este derecho innovador, pues sin él no se hubiese generado el desarrollo que tuvo la actividad comercial en su momento. Esto sería imposible sin la creación del Pagaré, las sociedades de responsabilidad limitada, la persona jurídica, el mutuo, la letra de cambio, que fue el resultado de la aplicación del este derecho y del desarrollo que los juristas de esta época consiguieron impulsados en la necesidad de ser innovadores y creativos, por lo que generaron una serie de figuras jurídicas que daban soluciones a los problemas de esta época y que permitieron innegablemente el desarrollo comercial durante esta etapa del desarrollo social de la humanidad, que ha permitido que en general el nivel de vida de los seres humanos, por lo menos en los tres últimos siglos sean muchísimos más altos, de los que tuvo la humanidad en general desde siempre hasta antes de este desarrollo del intelecto y habilidades humanas sostenido en esencia en la urgencia de hacer más eficiente el atender las diversas necesidades de las personas en general que directa e indirectamente son atendidas por medio del mercado de manera eficiente.

Encontramos luego, que, en el desarrollo social de la humanidad, que el concepto de Estado y su consolidación se va fortaleciendo, y surgen los primeros Estado Nación, este hecho innegablemente genera evidentemente una incongruencia entre este derecho consuetudinario, sin fronteras, innovador, de costumbres, eficiente y cambiante y surge un nuevo derecho vinculado al concepto de Estado que es mucho más acotado a lo que constituye su feudo, sus límites, sus fronteras naturales. Es sencillo entender que esto generó naturalmente un duro enfrentamiento entre la manera como se manejó el derecho en esta época y la manera como se hizo posteriormente con el surgimiento del concepto nación.

Esta época moderna y de desarrollo social tuvo sus virtudes pero limitó objetivamente el desarrollo de este Derecho Transnacional, sin embargo, en la misma época y, conforme evoluciona y crece la actividad comercial comienzan a aparecer un gran número de empresas y sociedades mercantiles que ya no operaban solamente a nivel local si no que tenían una serie de clientes y consumidores en otras naciones y muy diversos lugares, desde allí y de esa necesidad es que surge lo que ahora entendemos como mundo globalizado, vinculado a un mercado global, mundial, sin fronteras ni límites, pues los grandes protagonistas en la actualidad del desarrollo económico de las naciones y de las economías mundiales son las grandes empresas transnacionales, las que objetivamente son imposibles de quedar sometidas a un solo ordenamiento jurídico nacional pues, realizan por su propia naturaleza y posibilidades económicas, actividades comerciales en múltiples estados. 
Este fenómeno, de desarrollo económico, además se ve sólidamente sostenido en el desarrollo tecnológico extraordinario que se da tanto en el campo de las comunicaciones con el internet, los celulares, sino también en la informática, los medios de transporte; por tanto los comerciantes actuales se encuentran ya no limitados a realizar actividad dentro de un estado sino que tiene todo mundo dónde poder expandir su actividad mercantil y maximizar su éxito comercial y económico sin los limites naturales que las fronteras estatales y sus mercados limitados les imponían.

Es evidente que las transnacionales han copado el mundo globalizado actual y su fortaleza está justamente en que no tienen un límite fronterizo que acoté, circunscriba o restrinja el desarrollo de sus actividades comerciales como lo dice Paolo Grossi "El mercado aparece, como nunca, intolerante a las limitaciones espaciales" 6 pues es evidente que en el mundo actual una nación con un mercado controlado o limitado, donde sus agentes económicos estén impedidos de interactuar libremente, son naciones que condenan a sus habitantes a una pobreza e inequidad absolutamente innecesarias, pues allí donde existen mercados libres, propiedad privada, derechos ciudadanos y sobre todo libertad, se encuentra prosperidad y mucho mejor nivel de las personas.

Debemos entender entonces que el moderno Derecho Comercial o Corporativo ha sobrepasado en mucho el derecho de carácter estatal, pues éste es un derecho limitado y fronterizo que es desbordado constantemente por una realidad económica que tiene una realidad transfronteriza y globalizada que evidentemente se sostiene, como en el pasado, en un fuerte ingrediente consuetudinario que, objetivamente, busca un derecho de naturaleza comercial que trascienda, como ocurre, las fronteras estatales, lo que el derecho moderno no les brinda y por lo tanto ha surgido la necesidad de crear un derecho transnacional vinculado a un nuevo orden económico internacional que se mueve en un ámbito absolutamente transnacional, transfronterizo e internacional que es un hecho que necesariamente debemos atender los juristas para lograr actualizar nuestra realidades legislativas y legales a este nuevo estatus y lograr, mediante ello, mantener la paz social y el orden mundial, actualizando sus conceptos, prácticas y normas a ésta nueva innegable realidad, que permita relaciones comerciales eficientes, justas y equitativas.

Dado el contexto actual; de desarrollo de la tecnología, medios de comunicación y producción; ha generado que el mundo actual y moderno tenga un vertiginoso cambio de estructuras, así como en las relaciones económicas internacionales que lo vincula. En este sentido, ya a inicios del siglo pasado, se ha establecido como criterio de los países más desarrollados que, es fundamental lograr para reducir las enormes desigualdades que existen en cuanto a la generación de riqueza y por ende del nivel de vida de los ciudadanos establecer un Nuevo Orden Económico Internacional, esto desde una perspectiva mundial y organizada.

A nivel de las Naciones Unidas se acunó un concepto vinculado a esta nueva estructura económica transfronteriza vinculado al concepto de Nuevo Orden Económico Internacional que propugnaba

6. P. Grossi, La formación del jurista y exigencia de una reflexión metodológica innovadora, op.cit, 155-156. 
ayudar a establecer relaciones económicas más justas y de esta manera a contribuir a mejorar el destino de las poblaciones de diversas partes del mundo, evidentemente sin descuidar la permanente ayuda humanitaria que siempre se tiene que brindar a poblaciones menos favorecidas.

Este Nuevo Orden Económico Internacional, debemos referir, que tiene como graves y preocupantes antecedentes la crisis económica de la década del 30 que afectó a las economías más importantes del planeta así como la Segunda Guerra Mundial, luego de lo cual, los países del mundo de manera organizada asumieron como verdad objetiva que el logro de la paz sería el resultante del desarrollo simultaneo y congruente de la seguridad política de los estados y de la necesaria prosperidad y mejora económica de sus pueblos, por lo menos a niveles de subsistencia decorosos.

Con esta lógica la comunidad internacional, dentro de las limitaciones que tuvo la realidad económica de la posguerra mundial, y, dentro de las características que esta realidad económica en ese difícil contexto tenía, fue elaborando un esquema conceptual para lograr mayor estabilidad en el mundo. Con esta realidad los objetivos principales que tenía en estas políticas consistieron en establecer una férrea disciplina monetaria, que aún ahora es fundamental respetar, que lograse primero contener la inflación y segundo lograr movilizar recursos para promover y acelerar la reconstrucción de los países seriamente afectados por el conflicto bélico y lograr promover cierta estabilidad económica a través de la expansión del comercio internacional sobre bases no discriminatorias.

\section{i. Sustento conceptual del nuevo orden económico internacional}

Esta difícil situación generó una visión diferente en la comunidad internacional frente a esta coyuntura, se han desarrollado una serie de elementos y características para atender este problema conjunto y universal que debemos destacar, y que tiene sustento principalmente en los siguientes argumentos:

(i) Debemos asumir que la sociedad internacional contemporánea. Se crea y surge a partir de la comunidad mundial organizada para lograr el desarrollo y económico de todas las naciones del mundo esto da origen a lo que ahora conocemos como llamado derecho internacional del desarrollo y surgió objetivamente de las diferencias sustantivas que se tenían entre los países desarrollados y aquellos que se encontraban en vías de desarrollo. Finalmente, este trabajo conjunto y organizado, es claro de entender, que se encuentren contenidos en diversas resoluciones y recomendaciones de organizaciones internacionales de muy variada de naturaleza e índole a las que haremos referencia posteriormente.

(ii) Tenemos entonces que el derecho internacional en general mejoró su orientación y claro está que esto se da a través de la creación y generación de valores mundiales que antes no se percibían o atendían y que tiene objetivos tales como la justicia social, el bien común y la determinación propia de cada nación en materia económica. Es evidente que estas decisiones determinan el mayor o menor desarrollo económico y por tanto mayor o menor calidad de vida de sus ciudadanos en función a las decisiones que cada nación, de manera independiente y particular, tome en el desarrollo de su evolución histórica. 
(iii) Un último pilar fundamental en esta manera diferente de concebir las relaciones entre estados es la de aceptar la concepción de la coexistencia pacífica entre naciones con regímenes políticos absolutamente diferentes, contrapuestos e inclusive enfrentados, lo cual cuando menos en el campo económico internacional ha generado la proclamación de los principios de la Carta de Naciones Unidas en relación con la tarea pendiente del desarrollo económico y la cooperación que se deben todas las naciones del mundo.

(iv) Consideramos que es importante también destacar que han surgido una serie de organismos internacionales, evidentemente transfronterizos, que son en buena medida responsables de la transformación experimentada por la sociedad internacional clásica. Organismos que en su mayoría surgieron, casi en su totalidad, después de la última conflagración mundial.

Estas organizaciones que debemos mencionar y destacar podrían ser, por ejemplo la UNCITRAL (Comisión de las Naciones Unidas para el Derecho Mercantil Internacional, CNUDMI o UNCITRAL, por su siglas en inglés United Nations Commission for the Unification of International Trade Law); el Fondo Monetario Internacional (Nace en julio de 1944 en los acuerdos de Bretton Woods una reunión de 730 delegados de 44 países aliados de la Segunda Guerra Mundial); el Banco Mundial; la FAO (que es la Organización de las Naciones Unidas para la Alimentación y la Agricultura ONUAA - o más conocida como FAO por sus siglas en inglés: Food and Agriculture Organization); la OIT (Organización Internacional del Trabajo, una entidad que funciona bajo la órbita de la Organización de las Naciones Unidas - ONU); CEPAL (Comisión Económica para América Latina y el Caribe, y es un organismo que funciona bajo la órbita de la Organización de las Naciones Unidas - ONU); entre otras varias organizaciones semejantes lo que de alguna manera le dan soporte a la nueva sociedad internacional del derecho internacional económico.

(v) Finalmente y casi como una consecuencia lógica de los nuevos preceptos económicos debe tomarse en cuenta la trascendental actividad desarrollada por las entidades privadas que sostenidas en el amplio margen de acción que les permite el ejercicio de la autonomía de la voluntad, que a su vez les ha permitido una amplia y activa participación en el comercio mundial han logrado incorporar practica y usos comerciales que se han incorporado en sus contratos como cláusulas que finalmente son modelos que se utiliza en esta actividad económica y que pasan a tener el carácter de verdaderos usos mercantiles internacionales, que finalmente, al lado de la costumbre son fuentes innegables del derecho.

Esta coyuntura mundial se presenta pues, muchos de los países que en los sesenta surgieron como naciones independientes, producto del proceso de descolonización iniciado en esa época, creyeron con eso obtenían su soberanía, sin embargo se dieron que en realidad no era tan fácil desarrollarse pues no tenían mayor soporte que permitiera ello, por lo que con un criterio objetivo percibieron que, para tener en realidad la posibilidad de tener normas y pautas internas, como también internacionales, que generasen progreso sostenido, necesitaban poder generar en sus naciones un desarrollo económico suficiente que les permitiera fortalecer sus estados y cimentar su soberanía. 


\section{ii. Las Naciones Unidas y el nuevo orden económico internacional}

Con la finalidad de poder garantizar aquello se emiten por parte de la Asamblea de la Naciones Unidas una serie de resoluciones que busquen lograr, o cuando menos garantizar, su desarrollo libre e independiente y sin injerencias ajenas, así tenemos la Resolución 1803, de fecha 14 de diciembre de 1962 (Soberanía permanente sobre los recursos naturales) ${ }^{7}$, la Resolución 2131 del 21 de diciembre del año 1965 (Declaración sobre la inadmisibilidad de la intervención en los asuntos internos de los Estados y protección de su independencia y soberanía) ${ }^{8}$, la Resolución 2542, del 11 de diciembre de 1969 (Declaración sobre el progreso y desarrollo en lo social) ${ }^{9}$; Resolución 2625 (Principios referentes a las relaciones de amistad y a la cooperación entre los estados) de fecha 24 de octubre de $1970^{10}$; la Carta de los Derechos y Deberes Económicos de los Estados, contenida en la Resolución 3281 de fecha 12 de diciembre de $1974^{11}$; la Resolución 3362, que se refiere al Desarrollo y a la Cooperación Económica Internacional, de fecha 16 de setiembre de $1975^{12}$, son las que de alguna u otra manera dieron origen y soporte al llamado Nuevo Orden Económico Internacional.

Continuando en esta lógica las Naciones Unidas han implementado por intermedio de su Asamblea General; los llamados Decenios para el Desarrollo, el primero del año 1960 al año 1970 y el segundo del año 1970 al año 1980, respectivamente. Lamentablemente la buena voluntad expresada en ellos no alcanzó y ya desde hace varios años los hechos y acontecimientos se presentaron de una manera tan diferente para los bloques de los países del primer mundo como para lo en vías de desarrollo, que los países del tercer mundo, casi al unísono, han propiciado y generado, cuando menos, reivindicaciones que son mucho más generales, universales, pero también más radicales, que aquellas específicas para lograr sólo su propio desarrollo económico.

7. United Nations Audiovisual Library of International Law. (2012). Resolución 1803 (XVII) de la Asamblea General, Relativa a la Soberanía Permanente sobre los Recursos Naturales. Unites Nations: Recuperado de https://legal.un.org/ avl/pdf/ha/ga_1803/ga_1803_ph_s.pdf

8. McWhinney, E. (2011). Resolución 2131 (XX) de la Asamblea General de 21 de diciembre de 1965, Declaración sobre la Inadmisibilidad de la Intervención en los Asuntos Internos de los Estados y Protección de su Independencia y Soberanía. United Nations: United Nations Audiovisual Library of International Law. Recuperado de https://legal.un.org/avl/ pdf/ha/ga_2131-xx/ga_2131-xx_s.pdf

9. Asamblea de las Naciones Unidas. Resolución 2542, del 11 de diciembre de 1969 (Declaración sobre el progreso y desarrollo en lo social). Recuperado de https://undocs.org/pdf?symbol=es/A/RES/2542(XXIV)

10. United Nations Audiovisual Library of International Law. (2017). Declaración sobre los principios de derecho internacional referentes a las relaciones de amistad y a la cooperación entre los Estados de conformidad con la Carta de las Naciones Unidas. Unites Nations: Recuperado de: https://legal.un.org/avl/pdf/ha/dpilfrcscun/dpilfrcscun_ph_s.pdf 11. United Nations Audiovisual Library of International Law. (2011). Resolución 3281 (XXIX) de la Asamblea General Carta de Derechos y Deberes Económicos de los Estados. Unites Nations: Recuperado de https://legal.un.org/avl/pdf/ ha/cerds/cerds_ph_s.pdf

12. Asamblea General de las Naciones Unidas. (1976). Desarrollo y Cooperación Económica Internacional: Aplicación de las Decisiones Adoptadas por la Asamblea General en su Séptimo Periodo Extraordinario de Sesiones. (A/31/33). Recuperado de file://C:/Users/ponce/Downloads/A_31_335-ES\%20(9).pdf 
Esto, como es de esperar, tiene implícitamente contenida la obligación de modificar el estatus quo que existía en relación a las normas relativas a las relaciones económicas internacionales y que se fundan en el reconocimiento de que el actual orden económico está en contradicción directa con la evolución de las relaciones políticas y económicas internacionales en el mundo contemporáneo, lo que muchas veces contrasta con posiciones mucho más radicales en la manera de enfrentar el manejo económico de las naciones con el objetivo común de maximizar el bienestar de los ciudadanos, con evidentes y marcadas diferencias entre los sistemas que buscan lograr ello.

Frente a estos hechos las Naciones Unidas ha tratado de alguna manera de contribuir con darle orden a las ideas y políticas generales que deben aplicarse por ello ya, a mediados de los años setentas se presentaron algunas reformas de los principios del Derecho Internacional del Desarrollo y de las normas del Derecho Internacional Económico, esto se acreditó en la Resoluciones 3201 y 3202 de la Asamblea General de las Naciones Unidas aprobadas el 1 de mayo de 1974 y tituladas Declaración sobre el establecimiento del Nuevo Orden Económico Internacional y Programa de acción sobre el establecimiento de un Nuevo Orden Económico Internacional, vinculado a ello tenemos la Resolución 3281 (Carta de Derechos y Deberes Económicos de los Estados) contienen, a decir del Embajador Chileno René Rojas Galdames ${ }^{13}$ "la base de las reivindicaciones perseguidas por los países del tercer mundo que conforman la nueva alternativa de la función del Derecho Internacional, referido al desarrollo de las naciones"

\section{iii. Bases del desarrollo del nuevo orden económico internacional}

En este sentido, convenimos con el embajador citado, que se han acreditado tres bases y objetivos fundamentales que se deben buscar y sostener para el soporte del Nuevo Orden Económico Internacional, a saber (i) Control de la inversión extranjera, (ii) Expansión del comercio mundial y, finalmente (iii) Cooperación en las relaciones económicas internacionales.

Para dar mayor ilustración a lo expuesto, y aunque en la actualidad muchas de estas reglas son ya son de uso generalizado y común, consideramos importante tener en claro, aunque sea muy sucintamente cada una de ellas:

\section{Control de la inversión extranjera.}

Aún que en nuestra realidad sería muy difícil de entender en la actualidad esta necesidad, están muy vinculados a establecer reglas y principios que establezcan de manera objetiva el derecho que tienen todos los estados del mundo de regular las inversiones extranjeras que reciban al interior de sus naciones de la manera y modo que consideren conveniente a sus intereses y además establecen también a que ninguno podría ser forzado a conceder un trato preferencial al capital extranjero. Esto, desde la perspectiva nacional, ha quedado clara e incuestionablemente especificado en nuestra constitución al

13. En un artículo denominado "El Nuevo Orden Internacional" mientras fue Embajador de Chile en España publicado en la Revista de Política Internacional número 166, noviembre-diciembre 1979 del Centro de Estudios Políticos y Constitucionales del Ministerio de la Presidencia, Relaciones con las Cortes y Memoria Democrática del Gobierno de España. 
establecerse en el artículo $63^{\circ}$ que tanto la inversión extrajera como la nacional reciben el mismo trato lo que de alguna manera garantiza la posibilidad de captar más capital extranjero ya que esto es fundamental para lograr masificar el desarrollo de actividades económicas y con ellas el natural progreso de las personas vinculadas a ellas.

Esto videntemente tiene un origen absolutamente diferente pues se establecía anteriormente la soberanía permanente sobre los recursos naturales a favor de los llamados estados desarrollados y esto inclusive se encontró contenido en sendas resoluciones de las Naciones Unidas, que contenían normas que establecían principios a favor de ellas de manera general,

Por ejemplo establecía que la expropiación sólo podría darse por una causal sólo de orden público y que además debía estar vinculado al pago una compensación justa y si se presentase alguna controversia podría hacerse uso de la legislación nacional pero dejaba claramente establecido que para llegar finalmente a resolver una controversia de manera definitiva era necesario recurrir al arbitraje, que como hemos referido es una figura que utiliza el ser humano desde que comenzó interrelacionarse comercialmente de manera de transfronteriza.

Estos principios mutaron, y pasaron a establecer principios tales como el derecho de las naciones en general de mantener soberanía permanente sobre sus recursos naturales y además de como poder determinar unilateralmente una compensación posible por el pago de ella e incluso la posibilidad de la remisión a la propia legislación nacional para la resolución de cualquier disputa. Finalmente, y ya en la actualidad debemos referir que esto ha mutado y tratan de lograrse mecanismos de solución mucho más eficientes y justos y sobre todo tratando de evitar el abuso. Entendemos que esto de alguna manera queda claramente contenido en los siguientes fundamentales principios:

1. Plena y permanente soberanía de todos los Estados sobre sus recursos naturales.

2. Derecho de todo Estado para salvaguardar dichos recursos y ejercer el control efectivo de los mismos incluyendo el derecho a la nacionalización.

3. Ningún Estado puede ser coartado en estos derechos por medio de la presión política, económica o de otro orden.

\section{Expansión del comercio mundial.}

En este extremo lo que se busca con determinadas resoluciones emitidas en las Naciones Unidas es asegurar, sin ningún tipo de cortapisa, una mayor participación en el mercado mundial para los países en desarrollo, que siempre han visto limitado este derecho y han sido de alguna u otra manera forzados a negociar y pactar en condiciones menos favorables.

Además, establece criterios que pasan fundamentalmente por establecer la posibilidad de su participación en el comercio internacional sin discriminación de ningún tipo, pero principalmente aquellos 
que estuvieran fundamentadas en diferencias de sistemas políticos, económicos o sociales, lo que lamentablemente en la última época ha sido alterado, pues, es evidente, que hay sanciones de naturaleza restrictiva al comercio para países con regímenes diferentes.

La realidad moderna nos muestra objetivamente que el desarrollo de los países está íntimamente relacionado con el desarrollo del incremento de su participación dentro del mercado mundial, esta es una realidad concreta e incuestionable. En esta línea estas resoluciones buscaron hacer congruente esta lógica con aquello que queda expresamente dispuesto en este sentido.

También tuvieron una serie de otras disposiciones en relación a la necesidad de la expansión de comercio mundial, sobre prácticas comerciales restrictivas, sobre promoción de exportaciones y reducción de barreras arancelarias, etc. Esto, en beneficio de las naciones en desarrollo, por lo menos en teoría, sigue en constante evolución y consideramos que cada vez es menos innegable que la prosperidad que el desarrollo tiene vinculado en sí mismo, se genera en la interacción libre de las naciones dentro de un mercado que permita recibir de manera equitativa, razonable y justa todo que lo que merecen los pueblos en mérito a su iniciativa privada, innovación, esfuerzo, desarrollo tecnológico y trabajo. Tarea cada vez más importante.

\section{Cooperación en las relaciones económicas internacionales.}

Dentro de una lógica mundial plausible, todas las disposiciones que tienen vinculación con este Nuevo Orden Económico Internacional proponen en general igualdad jurídica de los estados dentro de, la que podríamos denominar, sociedad internacional y está también se logra con el desarrollo igualitario de la seguridad económica de los países menos desarrollado. Este objetivo sería importante de alcanzar para el bienestar mundial, sin embargo, entre tanto como están redactadas estas disposiciones permitiría que todos los estados del mundo participen plenamente en las decisiones que tengan relación con el futuro desarrollo de la economía mundial en todos los aspectos y ésta es una nota distintiva fundamental en el concepto de las disposiciones vinculadas a esta materia que debemos valorar y destacar.

Debemos resaltar también que estas resoluciones de las naciones unidas busca en buena cuenta que los países desarrollados con aquellos envía de desarrollo puedo tener una colaboración constante y permanente que permita finalmente facilitar el funcionamiento de un sistema más racional y equitativo en las relaciones internacionales, si esto que comentamos se lograse, debería impulsar una serie de cambios sustantivos en cómo se ve la economía mundial teniendo, en esta lógica, en consideración las gigantescas necesidades que tienen las naciones en desarrollo

Así muchas de estas resoluciones busca que las naciones en desarrollo logren su prosperidad económica de manera particular y establecen también medidas que permitan alentar la industrialización de estos países y además propugna que se hagan los mayores esfuerzos para que se les permita acceso, a los países menos adelantados, a las nuevas tecnologías, en las mejores condiciones posibles, evidentemente para que esto sea congruente con las condiciones económicas, culturales y ecológicas del mundo 
moderno. Esto evidentemente es la mejor manera de lograr mayor equidad en un mundo aún muy desigual lo que genera la innecesaria inestabilidad mundial, que muchas veces nos abruma.

Debemos manifestar que ésta es una lucha constante y permanente entre aquellos países que tienen prosperidad económica y los más pobres y con sistemas económicos diferentes, por lo que es fundamental trabajar en la lógica de una solidaridad mundial que permita tratar de igualar o reducir lo más que se pueda las enormes diferencias que tienen los estados en el mundo; lo que hace que aún en pleno siglo XXI existan ingentes cantidades de personas huyendo del hambre, la miseria y el subdesarrollo hacia naciones y latitudes con mucha mayor prosperidad.

\section{EL NUEVO ORDEN ECONÓMICO INTERNACIONAL Y SU NECESARIA ACTUALIZACIÓN}

Es evidente que en la actualidad subsisten grandes problemas de orden económico, incluso en los países más desarrollados que también están sufriendo estas crisis y lo lamentable es que tratan de solucionarlo con políticas de muy corto plazo y que sólo atienden la parte interna y particular de su crisis, desconociendo todos estos principios que existen y que de alguna manera generarían, con una visión más amplia por parte de estas naciones, un desarrollo más equilibrado en el mundo, lo que hace necesario conocer el concepto acuńado a nivel de las Naciones Unidas; acotado a esta nueva estructura económica transfronteriza; como Nuevo Orden Económico Internacional, que propugnaba ayudar a establecer relaciones económicas más justas y de esta manera a contribuir a mejorar el destino de las poblaciones de diversas partes del mundo, por lo que para lograr este objetivo sería necesario interiorizar en las políticas internacionales de las naciones en desarrollo el respeto irrestricto de las ideas propugnadas vinculadas a este concepto y que hemos tratado mediante el presente trabajo de presentar.

Pues si no observan objetivamente que existen evidentes e innegables vínculos causales estrechos entre las políticas que los países desarrollados imponen con políticas circunstancialmente discriminadoras con los menos desarrollados no van a lograr una recuperación económica sostenible y generalizada que pueda mantenerse en el tiempo, lo que creemos se debe atender de manera diligente, objetivo con el que consideramos se debe contribuir, en lo que corresponde, de manera objetiva y concreta, al tratar de establecer la conveniencia de integrar legislación transfronteriza en los ordenamientos jurídicos. Pues siempre "el Derecho Internacional Privado persigue realizar un especifico ideal de justicia en las relaciones transfronterizas, garantizando su continuidad en el espacio y su previsibilidad" ${ }^{14}$, sin embargo es objetivamente imposible alcanzar una unificación completa del derecho sustantivo, a nivel universal o internacional, por lo que es necesario que los Estados puedan incorporar de forma independiente y autónoma en su legislación interna, normas para resolver problemas de naturaleza económico empresarial, que con mayor complejidad cada día trae el intercambio transnacional de bienes y servicios en el

14. C. Nieto Delgado, PRACTICUM CONCURSAL 2018 Concurso con elemento de extranjería y derecho internacional privado, (Madrid: Thomson Reuters, Editora Arazandi 2018), 907-908. 
mundo entero, con la finalidad de pretender resolver las cada vez más difíciles relaciones comerciales y patrimoniales con elemento internacional que se presentan.

En este sentido es importante hacer notar que ya incluso a nivel de las Naciones Unidas hay esfuerzos sinceros por lograr un equilibrio mundial mediante el desarrollo de todos los países en su conjunto, pues es evidente que la única manera de lograr bienestar común es logrando que los ciudadanos del mundo puedan desarrollar sus capacidades y actividades en una nación con posibilidades para que ello ocurra, donde el bienestar que políticas económicas responsables, serias y adecuadas puede traer consigo y lograr además seguridad jurídica e inversión que se canaliza siempre a donde existen reglas claras, respeto a la propiedad, instituciones sólidas y seguridad jurídica, que es un esfuerzo en el que debemos contribuir todos los que estamos involucrados en el mundo del derecho, pues está es la única manera de lograr equidad, paz y bienestar colectivo.

\section{REFERENCIAS}

- Asamblea General de las Naciones Unidas. (1976). Desarrollo y Cooperación Económica Internacional: Aplicación de las Decisiones Adoptadas por la Asamblea General en su Séptimo Periodo Extraordinario de Sesiones. (A/31/33). Recuperado de: file://C:/Users/ponce/Downloads/A_31_335-ES\%20(9).pdf

- Asamblea de las Naciones Unidas. Resolución 2542, del 11 de diciembre de 1969 (Declaración sobre el progreso y desarrollo en lo social). Recuperado de https://undocs.org/pdf?symbol=es/A/RES/2542(XXIV)

- De Trasegnies Granda, F. “¿Lex mercatoria rediviva? Primera parte: De la edad media a la pos modernidad”. Revista Peruana de Arbitraje N³, (2006):15-51.

- Grossi, P. La formación del jurista y exigencia de una reflexión metodológica innovadora. México: Escuela Libre de Derecho de la Universidad Michoacana de San Nicolás Hidalgo, 2004.

- Larroument, C. Internacionalizacion del Derecho en un Mundo Globalizado. Lima: Fondo Editorial de USMP, 2008.

- McWhinney, E. Resolución 2131 (XX) de la Asamblea General de 21 de diciembre de 1965 Declaración Sobre la Inadmisibilidad de la Intervención en los Asuntos Internos de los Estados y Protección de su Independencia Y Soberanía. United Nations: United Nations Audiovisual Library of International Law, 2011. Recuperado de https://legal.un.org/avl/pdf/ha/ga_2131-xx/ga_2131-xx_s.pdf https://undocs.org/pdf?symbol=es/A/RES/2542(XXIV) 
- $\quad$ Nieto Delgado, C. PRACTICUM CONCURSAL 2018 Concurso con elemento de extranjería y derecho internacional privado. Madrid: Thomson Reuters, Editora Arazandi, 2018.

- Rojas Galdames., R. Centro de Estudios Politicos y Constitucionales del Ministerio de la Presidencia, España. Diciembre de 1979. Recuperado de : http://www.cepc.gob.es/publicaciones/revistas/fondohistorico?IDR=13\&IDN=1197\&IDA=34915

- United Nations Audiovisual Library of International Law. (2017). Declaración sobre los principios de derecho internacional referentes a las relaciones de amistad y a la cooperación entre los Estados de conformidad con la Carta de las Naciones Unidas. Unites Nations: Recuperado de https://legal.un.org/avl/pdf/ha/dpilfrcscun/dpilfrcscun_ph_s.pdf

- $\quad$ United Nations Audiovisual Library of International Law. (2011). Resolución 3281 (XXIX) de la Asamblea General Carta de Derechos y Deberes Económicos de los Estados. Unites Nations: Recuperado de https://legal.un.org/avl/pdf/ha/cerds/cerds_ph_s.pdf

- $\quad$ United Nations Audiovisual Library of International Law. (2012). Resolución 1803 (XVII) de la Asamblea General, Relativa a la Soberanía Permanente sobre los Recursos Naturales. Unites Nations: Recuperado de https://legal.un.org/avl/pdf/ha/ga_1803/ga_1803_ph_s.pdf

RECIBIDO: 30/10/2020

APROBADO: $15 / 11 / 2020$ 